\title{
Neighbor identity and competition influence tree growth in Scots pine, Siberian larch, and silver birch
}

\author{
Pekka KAITANIEMI $^{1 *}$, Anna LinTUNEN ${ }^{2}$ \\ ${ }^{1}$ Hyytiälä Forestry Field Station, University of Helsinki, Hyytiäläntie 124, 35500 Korkeakoski, Finland \\ ${ }^{2}$ Department of Forest Ecology, University of Helsinki, P.O. Box 27, 00014 University of Helsinki, Finland
}

(Received 31 August 2009; accepted 8 January 2010)

\begin{abstract}
Keywords:
boreal forest /

competition /

mixed stand /

tree growth
\end{abstract}

\begin{abstract}
- Previous studies on competitive interactions among silver birch, Scots pine, and Siberian larch have not addressed the direct importance of the species identity of nearby competitors.

- We examined the joint importance of competition and species identity, using subject trees with a high local abundance of a single dominant neighboring species. Interspecific neighbors influenced annual height increment, shoot length, and branch number per unit crown length, especially in Scots pine. Silver birch and Siberian larch were predominantly affected by the level of competition alone, as estimated with competition indices.

- In Scots pine, the effects may have been a direct consequence of the species identity of neighbors or they may have acted as a substitute for the effect of some non-measured variable associated with species-specific characteristics. These functionally equivalent alternatives suggest that simple indices are not adequate measures of the neighbor effect for Scots pine.

- A simple extrapolation of individual tree growth to the stand level suggested that Scots pine and silver birch may grow faster in mixed than in pure stands. Siberian larch showed negative growth responses to interspecific neighbors, but the effects may be counterbalanced at the stand level by a corresponding increase in pine or birch growth.
\end{abstract}

\section{INTRODUCTION}

The potential importance of competitive species interactions for tree growth is well recognized (e.g. Casper and Jackson, 1997; Goldberg and Barton, 1992), and has been demonstrated in many case studies in forestry (e.g. Canham et al., 2004; De Luis et al., 1998; Mielikäinen, 1980; Rivas et al., 2005). However, the practical value of this information has often been underrated, due to the commercial demands favoring monocultures (Kelty, 2006; Nichols et al., 2006). Requirements for sustainable management have increased the preference for species mixtures and there is a growing need for studies covering different aspects of tree cultivation and competition in mixed stands (Knoke et al., 2008).

Mixed forests with variable combinations of silver birch (Betula pendula Roth), Scots pine (Pinus sylvestris L.), and Siberian larch (Larix sibirica Ledeb.) are native to the boreal forest zone of Europe and Russia, where they often belong to the major vegetation types (Shorohova et al., 2009). They form a species group for which information on mutual interactions is likely to benefit management decisions, since they have wide economic use and are species whose relative distributions are expected to change under conditions of changing

*Corresponding author: pekka.j.kaitaniemi@helsinki.fi climate (Tchebakova et al., 2003). Previous studies on these species have focused on stand-level yield responses, especially in the admixtures of Scots pine and silver birch where interactive effects on tree growth have been observed (Frivold and Frank, 2002; Lappi-Seppälä, 1930; Mielikäinen, 1980; Valkonen and Ruuska, 2003). Previous studies have not usually separated the direct importance of species identity from the effect of spatial arrangement of different species within the stand. Valkonen and Ruuska (2003) included a competition index $(\mathrm{CI})$ to characterize the direct effect of neighbors, but considered only young stands with 2-8-m dominant height and competitors at less than $2-\mathrm{m}$ distance from the target trees. The competitive yield responses of Siberian larch seem not to be covered in the literature.

In order to distinguish the effects of the level of competition from the species identity of neighboring trees, we examined the growth responses of 4- to 35-year-old target trees competing under a high abundance of one out of the three alternative neighboring species in turn. The target trees were selected to have a high local abundance of a single dominant neighboring species to directly assess the importance of neighbor species identity. A set of 12 CIs was used to characterize the strength of competition in the presence of different neighbors. Average height increment over time, a time series of increase in diameter, length of annual shoots, and number of living branches per 
Table I. Number of study trees growing with different neighboring species at study sites. The average basal area $\left(\mathrm{m}^{2} / \mathrm{ha}\right)$ and site index of each stand is also given.

\begin{tabular}{|c|c|c|c|c|c|c|c|c|c|c|c|}
\hline \multirow[b]{2}{*}{ Site } & \multirow{2}{*}{$\begin{array}{c}\text { Basal area } \\
\left(\mathrm{m}^{2} / \mathrm{ha}\right)\end{array}$} & \multirow{2}{*}{$\begin{array}{c}\text { Site } \\
\text { index* }\end{array}$} & \multicolumn{3}{|c|}{$\begin{array}{c}\text { Silver birch } \\
\text { with }\end{array}$} & \multicolumn{3}{|c|}{$\begin{array}{l}\text { Scots pine } \\
\text { with }\end{array}$} & \multicolumn{3}{|c|}{$\begin{array}{l}\text { Siberian larch } \\
\text { with }\end{array}$} \\
\hline & & & Birch & Pine & Larch & Birch & Pine & Larch & Birch & Pine & Larch \\
\hline$\overline{\mathrm{AH}}$ & 10 & 24 & 3 & 3 & - & 3 & 3 & - & - & - & - \\
\hline $\mathrm{KO}$ & 15 & 22 & 3 & 3 & - & 3 & 3 & - & - & - & - \\
\hline JO & 19 & 30 & 3 & 3 & - & 3 & 3 & - & - & - & - \\
\hline $\mathrm{KJ}$ & 25 & 26 & 3 & 2 & - & 2 & 2 & - & - & - & - \\
\hline PM & 12 & 22 & 3 & 3 & - & 3 & 3 & - & - & - & - \\
\hline PO & 1.2 & 26 & 4 & 3 & 3 & 4 & 6 & 3 & 4 & 2 & 3 \\
\hline PR & 0.5 & 24 & 6 & - & 1 & 6 & 4 & 1 & 3 & - & 3 \\
\hline JK & 8 & 22 & 1 & 2 & 1 & - & 4 & 3 & 2 & 3 & 4 \\
\hline SK & 19 & 22 & - & 2 & - & 2 & - & 2 & 1 & - & 2 \\
\hline $\mathrm{KP}$ & 25 & 24 & 2 & - & 2 & 3 & 2 & - & 2 & 2 & 2 \\
\hline $\mathrm{KV}$ & 18 & 22 & 1 & 1 & 1 & 1 & 3 & 3 & 1 & 1 & 3 \\
\hline $\mathrm{AK}$ & 13 & 22 & 2 & 2 & 3 & 2 & 2 & 2 & 2 & 1 & 3 \\
\hline Total & & & 31 & 24 & 11 & 32 & 35 & 14 & 15 & 9 & 20 \\
\hline
\end{tabular}

* Site index gives the estimated main height (mean height of 100 trees per ha with highest diameter-at-breast-height in the 50-year-old trees) for Betula pendula in southern Finland (taken from Lintunen and Kaitaniemi, 2010).

unit crown length were among the characteristics measured from the target trees and used to estimate the magnitude of both short- and long-term competitive growth responses with different neighbors.

\section{MATERIAL AND METHODS}

\subsection{Experimental design}

The study was designed to prioritize for a representative geographical range within Finland. The study area covered 12 sites along a $400-\mathrm{km}$ southwest-northeast transect between latitudes $60^{\circ} \mathrm{N}$ and $63^{\circ} \mathrm{N}$ and longitudes $21^{\circ} \mathrm{E}$ and $29^{\circ} \mathrm{E}$ in the boreal forest zone of Finland. Along this transect, the median distance between adjacent study sites was $15 \mathrm{~km}$ and the number of trees per species combination at individual study sites was typically between two and four (Tab. I). All the sites were defined in the local forest management plans as largely homogeneous areas, which did not include notable within-stand variation in characteristics such as site index, soil moisture, elevation etc. The stands were experimentally established or otherwise planted mixed stands representing Myrtillus forest site types characterized by mesic till soils and medium fertility. The elevation of sites ranged from 130 to $200 \mathrm{~m}$ above sea level, except for the two youngest stands (PO and PR in Tab. I) reaching only 20 to $50 \mathrm{~m}$. The study plots were located inside the larger stands and mostly consisted of up to 50-m $\times 50$-m plots in which the target species was abundant together with at least one of the neighboring species (Tab. I). Siberian larch was present only at seven sites.

Trees accepted as study trees were healthy-looking individuals surrounded by neighboring trees that had crowns adjacent to those of the target trees. This criterion ensured that the characteristics of the target trees properly reflected the potential effects of ongoing and past competition for light. The study trees represented 4-35-year-old individuals, and hence covered the developmental phase during which growth is fastest and the trees establish their competitive status. The study trees and their neighbors consisted of planted and occasionally also naturally regenerated individuals. The size and age of trees selected within each site were as uniform as possible, with the average coefficient of variation for both the age and height of trees within the sites being $13-21 \%$, depending on tree species. Among the sites, the average coefficient of variation was $44-62 \%$ for tree age and 56-68\% for tree height. Stands representing different ages or height classes were always replicated such that there were at least two sites with a maximum 3-y difference in the average tree age or a 2-m difference in the average tree height. Thus, in accordance with a fractional factorial sampling design (JMP Design of Experiments, Release 6, SAS Institute, Cary, NC, USA), the available combinations of tree and stand characteristics (Tab. I) partially overlapped to facilitate the analysis of ecologically interesting effects.

The choice and definition of neighboring trees emphasized the potential effect of crown interactions, because the neighboring trees were defined as those that either touched or were potentially able to touch the study tree crown by growing their current branches straight through an open space within a 5-m radius cylinder centered at the stem base of the study tree. Each neighboring tree was characterized by its distance to the subject tree $\left(L_{i j}\right)$, diameter at breast height $\left(d_{j}\right)$, and tree height $\left(h_{j}\right)$. In general, the neighboring trees were approximately as high as the study trees, and the average difference in height was not significantly different from zero, except for silver birch, which had birch and pine neighbors 1-1.5 $\mathrm{m}$ shorter than the subject trees.

The dominant neighboring species, in turn, was defined as the one with the sum of basal areas being over half (typically close to $80 \%$ ) of the total sum of basal areas of all the neighboring trees. The overall stand density was estimated using circular plots with either a 5-m (two youngest stands only) or with a $10-\mathrm{m}$ radius. The basal area of the stands was typically between 10 and $25 \mathrm{~m}^{2}$ /ha (Tab. I) and below the limit at which thinning is recommended in Finland (Anon., 2001). 


\subsection{Measurements and data analysis}

Both long- and short-term aspects of tree performance and neighbor effects were covered with the variables measured for each subject tree. Long-term effects of neighbors on tree growth were assessed with average annual height increment, which was calculated as tree height divided by tree age. The height was measured with a tape measure after felling the tree, and age was estimated by calculating the number of growth rings at the stem base. The true ages of the trees were slightly underestimated, because the stem samples were usually taken 20-30 cm above the ground. For Scots pine, whorl distances up to the 10 most recent fully developed whorls at the crown top were used to directly measure the annual amount of height growth. Longterm growth in diameter was examined by measuring the width of the annual growth rings from the 10 most recent years, if available. The growth rings were measured from a disk sample taken at the base of the tree stems.

For Scots pine and silver birch, short-term growth responses were also assessed. This was done by measuring the average length of 1- and 2-year-old shoots from a sample that covered the crown top and two to five branches systematically sampled from all vertical crown portions. To estimate the expansion rate of the entire crown, the shoot length was calculated as proportional to the total length of the branches or crown parts where the shoots were measured. The total length included the length of all branches at all branching orders, and was measured by digitizing the entire three-dimensional structure of the branches (Sinoquet and Rivet, 1997). To obtain an estimate of branch production with potential implications for timber quality (Kellomäki et al., 1999), the number of living branches per unit crown length was counted for Scots pine and silver birch.

A set of 12 CIs was used as covariates to facilitate partitioning the effects of competition and neighboring species identity. The indices were $\mathrm{CI}_{1}-\mathrm{CI}_{12}$ developed by Rouvinen and Kuuluvainen (1997) to study crown competition, and they operated with various combinations of $d_{j}, L_{i j}$ and $h_{j}$ of competitors and the subject tree to indicate the intensity of competition (Tab. II). The use of the present competition to explain past growth was considered adequate because the measured time span of growth was relatively short. For example, De Luis et al. (1998) found that integration of up to $10 \mathrm{y}$ of radial growth improved the precision of growth prediction based on the use of a CI. We assumed that the present values for the CIs correlated with their previous values, because all the study species are fast-growing pioneer species and because the stands had not undergone any recent thinning operations.

Statistical tests were conducted with the SAS procedure MIXED (Littell et al., 1996), which is suitable for unbalanced data that include random factors. All analyses included neighboring species as a fixed factor and site as a random factor. The CIs were examined as covariates. Since it was not meaningful to include all the indices in a single analysis, the explanatory power of each index in combination with other explanatory factors was examined to determine best-performing index. Akaike's Information Criterion (AIC; Akaike, $1973)$ with a correction for small samples $\left[A I C_{C i}=-2 \log L_{i}+2 V_{i}+\right.$ $2 V_{i}\left(V_{i}+1\right) /\left(n-V_{i}-1\right)$, in which $L_{i}$ is the maximum likelihood of model $i, V_{i}$ is the number of parameters estimated from the data for model $i$, and $n$ is the sample size] was used to assess the explanatory power of different indices. Only the final models are presented in the results. Interaction between the dominant neighboring species and the CI selected for the final model was also always examined, and retained in the final model if significant.
Table II. Competition indices examined in the study as taken from Rouvinen and Kuuluvainen (1997). Index $i$ denotes the subject tree and $j$ the competitor, $n$ is the number of competitors inside a 5-m radius from the subject tree, $h_{i}$ is the height of the subject tree, $h_{j}$ is the height of the competitor, $d_{i}$ is the DBH of the subject tree, $d_{j}$ is the $\mathrm{DBH}$ of the competitor, and $L_{i j}$ is the distance between the subject tree and the competitor.

$$
\begin{aligned}
& C I_{1}=\sum_{j=1}^{n} \arctan \left(d_{j} / L_{i j}\right) \\
& C I_{2}=\sum_{j=1}^{n} \arctan \left(d_{j} / L_{i j}\right), d_{j}>d_{i} \\
& C I_{3}=\sum_{j=1}^{n}\left(d_{j} / d_{i}\right) \arctan \left(d_{j} / L_{i j}\right) \\
& C I_{4}=\sum_{j=1}^{n} \arctan \left(d_{j} / L_{i j}\right), h_{j}>h_{i} \\
& C I_{5}=\sum_{j=1}^{n} \arctan \left(h_{j} / L_{i j}\right), h_{j}>h_{i} \\
& \left.C I_{6}=\sum_{j=1}^{n} \arctan \left[h_{i}-0.8 h_{j}\right) / L_{i j}\right], h_{j}>0.8 h_{i} \\
& C I_{7}=\sum_{j=1}^{n} \arctan \left(h_{j} / L_{i j}\right), h_{j}>h_{i} / 2 \\
& C I_{8}=\sum_{j=1}^{n} \arctan \left[\left(h_{j}-h_{i}\right) / L_{i j}\right], h_{j}>h_{i} \\
& C I_{9}=\sum_{j=1}^{n} \frac{d_{j}}{L_{i j}} \\
& C I_{10}=\sum_{j=1}^{n} \frac{d_{j} / d_{i}}{L_{i j}} \\
& C I_{11}=\sum_{j=1}^{n} \frac{d_{j} / d_{i}}{L_{i j}^{2}} \\
& C I_{12}=\sum_{j=1}^{n} \frac{\left(d_{j} / d_{i}\right)^{2}}{L_{i j}}
\end{aligned}
$$

Additional covariates were utilized in the analyses of whorl distances (Scots pine only) and long-term diameter growth. These analyses included both the year of growth and tree age, which were used to control the effects of variation in annual growth and developmental stage, respectively. Measurements describing the same trees during different years were considered as repeated measurements made of the same individuals, and an autoregressive covariance structure with a time step of $1 \mathrm{y}$ was assumed for the effect of year. These models were fitted as multilevel models (Singer, 1998), in which site and tree within site were defined as random parameters.

As a result of the unbalanced data, Kenward-Roger estimates of the denominator degrees of freedom were used for the tests of fixed effects (Spilke et al., 2005). To meet the normality assumption, logtransformed data were used for growth-ring width in silver birch and Siberian larch and for branch number in Scots pine.

\section{RESULTS}

In silver birch, the average annual height increment was influenced by the interactive effect of $\mathrm{CI}_{6}$ and the identity of dominant neighboring species (Tab. IIIa). In contrast with conspecifics (considered as a control with slope $=0$ ), an increase in $\mathrm{CI}_{6}$ accelerated height growth in silver birch surrounded by Siberian larch (slope $=0.05$ with \pm 0.05 as $95 \%$ confidence interval) or Scots pine (slope $=0.07 \pm 0.04$ ). 
Table III. Results of mixed models testing the effect of neighboring species and competition indices (CI, see Tab. II) on different growth variables in silver birch. Diameter growth was analyzed as repeated measures using diameter growth of the latest $10 \mathrm{y}$. Sb, Sp, and $\mathrm{Sl}$ give the mean value $( \pm 95 \%$ confidence interval) of each response variable with silver birch, Scots pine, and Siberian larch as neighbors, respectively.

\begin{tabular}{|c|c|c|c|c|c|c|c|c|}
\hline Variable & Effect & Num $\mathrm{d} f$ & Den $\mathrm{d} f$ & $F$ & $P$ & $\mathrm{Sb}$ & $\mathrm{Sp}$ & S1 \\
\hline \multicolumn{6}{|c|}{ Height increment (cm/year) } & $49.1(7.9)$ & $54.3(8.0)$ & $54.4(10.0)$ \\
\hline & Neighbor & 2 & 37.3 & 2.7 & 0.0812 & & & \\
\hline & $\mathrm{CI}_{6}$ & 1 & 45.4 & 1.1 & 0.2963 & & & \\
\hline & $\mathrm{CI}_{6} \times$ neighbor & 2 & 39.2 & 9.1 & 0.0006 & & & \\
\hline \multicolumn{6}{|c|}{ Diameter growth (mm/year) } & $2.3(1.3)$ & $2.7(1.3)$ & $2.8(1.4)$ \\
\hline & Neighbor & 2 & 24.2 & 1.5 & 0.2541 & & & \\
\hline & Year & 9 & 230 & 1.3 & 0.2464 & & & \\
\hline & Age & 1 & 31.2 & 9.1 & 0.0052 & & & \\
\hline & $\mathrm{CI}_{6}$ & 1 & 28.6 & 9.9 & 0.0039 & & & \\
\hline \multicolumn{6}{|c|}{ Shoot length (annual shoot length/total branch length, cm) } & $0.11(0.04)$ & $0.11(0.04)$ & $0.13(0.05)$ \\
\hline & Neighbor & 2 & 60.3 & 0.2 & 0.8329 & & & \\
\hline & $\mathrm{CI}_{1}$ & 1 & 15.3 & 14.6 & 0.0016 & & & \\
\hline \multicolumn{6}{|c|}{ Branch number (branches/cm crown length) } & $0.10(0.01)$ & $0.11(0.01)$ & $0.11(0.02)$ \\
\hline & Neighbour & 2 & 46.5 & 2.1 & 0.1368 & & & \\
\hline & $\mathrm{CI}_{6}$ & 1 & 41 & 2.6 & 0.1147 & & & \\
\hline
\end{tabular}

Table IV. Results of mixed models testing the effect of neighboring species and competition indices (CI, see Tab. II) on different growth variables in Scots pine. Diameter growth was analyzed as repeated measures using diameter growth of the latest $10 \mathrm{y}$. Sb, $\mathrm{Sp}$, and $\mathrm{Sl}$ give the mean value ( $\pm 95 \%$ confidence interval) of each response variable with silver birch, Scots pine, and Siberian larch as neighbors, respectively.

\begin{tabular}{|c|c|c|c|c|c|c|c|c|}
\hline Variable & Effect & Num $\mathrm{d} f$ & Den $\mathrm{d} f$ & $F$ & $P$ & $\mathrm{Sb}$ & $\mathrm{Sp}$ & Sl \\
\hline \multicolumn{6}{|c|}{ Height increment (cm/year) } & $42.7(5.3)$ & $40.1(5.3)$ & $42.3(5.6)$ \\
\hline & Neighbor & 2 & 64.4 & 2.6 & 0.0801 & & & \\
\hline & $\mathrm{CI}_{11}$ & 1 & 65.3 & 10.1 & 0.0023 & & & \\
\hline \multicolumn{6}{|c|}{ Diameter growth (mm/year) } & $2.7(0.5)$ & $2.8(0.5)$ & $3.3(0.7)$ \\
\hline & Neighbor & 2 & 12.8 & 1.8 & 0.2002 & & & \\
\hline & Year & 9 & 381 & 20.9 & $<0.0001$ & & & \\
\hline & Age & 1 & 21.9 & 0.1 & 0.7142 & & & \\
\hline & $\mathrm{CI}_{1}$ & 1 & 14.5 & 0.1 & 0.7637 & & & \\
\hline \multicolumn{6}{|c|}{ Shoot length (annual shoot length/total branch length, $\mathrm{cm}$ ) } & $3.1(0.5)$ & $3.6(0.4)$ & $4.1(0.7)$ \\
\hline & neighbor & 2 & 73.4 & 3.6 & 0.0322 & & & \\
\hline & $\mathrm{CI}_{4}$ & 1 & 57.7 & 12.9 & 0.0007 & & & \\
\hline \multicolumn{6}{|c|}{ Branch number (branches/cm crown length) } & $0.10(0.02)$ & $0.11(0.02)$ & $0.13(0.02)$ \\
\hline & Neighbor & 2 & 62.3 & 4.1 & 0.0204 & & & \\
\hline & $\mathrm{CI}_{4}$ & 1 & 67 & 5.4 & 0.0231 & & & \\
\hline \multicolumn{6}{|c|}{ Whorl distance $(\mathrm{cm})$} & $51.9(6.5)$ & $47.6(6.5)$ & $47.9(6.7)$ \\
\hline & Neighbor & 2 & 138 & 3.7 & 0.0278 & & & \\
\hline & Year & 9 & 500 & 13.9 & $<0.0001$ & & & \\
\hline & age & 1 & 30.5 & 2.5 & 0.4013 & & & \\
\hline & $\mathrm{CI}_{4}$ & 1 & 138 & 2.6 & 0.0996 & & & \\
\hline
\end{tabular}

While the effect of dominant neighboring species on average height increment was only marginally significant in Scots pine (Tab. IVa), it became highly significant when whorl distances of up to the 10 most recent years were directly used to examine height growth (Tab. IVe). Both whorl distance and average height increment indicated that height growth was fastest with silver birch as neighbors (Tab. IVa, e). $\mathrm{CI}_{11}$ had a significant effect only on the average annual height increment of
Scots pine (Tab. IVa), which suggested a negative relationship between height growth and competition (slope $=-1.1 \pm 0.7$ ).

The average height increment of Siberian larch was influenced only by $\mathrm{CI}_{6}$ (Tab. Va) and the relationship was positive (slope $=2.6 \pm 1.7$ ). In silver birch, the width of the growth rings (Tab. IIIb) was directly reduced by $\mathrm{CI}_{6}$ (slope $=-0.11 \pm 0.08$ ). In Siberian larch, the effect of $\mathrm{CI}_{2}$ was dependent on the neighboring species (Tab. Vb), being strongest in the presence of 
Table V. Results of mixed models testing the effect of neighboring species and competition indices (CI, see Tab. II) on different growth variables in Siberian larch. Diameter growth was analyzed as repeated measures using diameter growth of the latest $10 \mathrm{y}$. Sb, Sp, and $\mathrm{Sl}$ give the mean value $( \pm 95 \%$ confidence interval) of each response variable with silver birch, Scots pine, and Siberian larch as neighbors, respectively.

\begin{tabular}{|c|c|c|c|c|c|c|c|c|}
\hline Variable & Effect & Num $\mathrm{d} f$ & Den $\mathrm{d} f$ & $F$ & $P$ & $\mathrm{Sb}$ & $\mathrm{Sp}$ & $\mathrm{Sl}$ \\
\hline \multicolumn{6}{|c|}{ Height increment (cm/year) } & $45.3(7.7)$ & $46.8(8.3)$ & $52.7(7.8)$ \\
\hline & Neighbor & 2 & 20.8 & 1.9 & 0.1688 & & & \\
\hline & $\mathrm{CI}_{6}$ & 1 & 23 & 9.8 & 0.0046 & & & \\
\hline \multicolumn{6}{|c|}{ Diameter growth (mm/year) } & $0.8(1.2)$ & $3.5(1.1)$ & $2.9(1.0)$ \\
\hline & Neighbor & 2 & 38.8 & 3.8 & 0.0307 & & & \\
\hline & Year & 9 & 215 & 2.8 & 0.0036 & & & \\
\hline & Age & 1 & 13.8 & 1.1 & 0.3230 & & & \\
\hline & $\mathrm{CI}_{2}$ & 1 & 40.8 & 31.1 & $<0.0001$ & & & \\
\hline & $\mathrm{CI}_{2} \times$ neighbor & 2 & 39 & 7.9 & 0.0013 & & & \\
\hline
\end{tabular}

silver birch (slope $=-11.77 \pm 6.36)$ and moderate with Scots pine (slope $=-3.96 \pm 3.61$ ) when Siberian larch neighbors were considered as controls (slope $=0$ ). In Scots pine, there was no effect of competition on growth rings (Tab. IVb).

In Scots pine, the average length of 1- and 2-year-old annual shoots was affected by the neighboring species and $\mathrm{CI}_{4}$ (Tab. IVc). The shortest shoots were produced in the presence of silver birch and the longest in the presence of Siberian larch. An increase in $\mathrm{CI}_{4}$ reduced shoot length. In silver birch, the length of 1-year-old shoots was directly reduced by $\mathrm{CI}_{1}$ (slope $=-0.04 \pm 0.02$, Tab. IIIc).

Significant effects of neighboring species and $\mathrm{CI}_{4}$ on branch number were detected in Scots pine, where branch number per crown length was highest with Siberian larch and lowest with silver birch as neighbors (Tab. IVd). $\mathrm{CI}_{4}$ had a negative effect on branch number (slope $=-0.81 \pm 0.71)$. No effects on branch number were detected in silver birch.

\section{DISCUSSION}

The identity of neighboring competitors directly influenced height increment, shoot length, and branch number in Scots pine. Interaction between neighbor identity and CI influenced height increment in silver birch and diameter growth in Siberian larch. The CIs alone affected at least some of the variables in all three species.

The findings suggest that the species identity of neighbors may affect growth of Scots pine, regardless of the level of competition. There are at least two alternative explanations for the observation: either the effects were a consequence of the identity of the neighboring species in itself or they acted as a substitute for the effect of some non-measured variable that was associated with species-specific characteristics. The exact mechanism cannot be concluded from our experiment because several factors may contribute to the responses. An example of a direct species-effect could be qualitative differences in the spectral composition of light reflected from the foliage of different neighboring species, which could elicit speciesspecific growth responses in the target tree (Quail, 2002). Nonmeasured variables, in turn, may include direct quantitative differences in traits, such as the level of light interception or root competition (Strand et al., 2006). Plants can also use wind velocities modified by neighbors as proximity signals (Aphalo and Ballaré, 1995), or experience direct crown collisions, which may decrease crown cover, branch length and shoot density of individual branches in the crown (Meng et al., 2006). Furthermore, the nutrient acquisition strategies of root systems may differ among boreal tree species (Kalliokoski et al., 2009).

Both direct or indirect species-specific effects remain plausible explanations, because the use of CIs as covariates may not have adequately accounted for differences in all tree characteristics that affect resource uptake by neighboring trees. More than $30 \%$ of the variation usually remains unexplained when different formulations of CIs are used to explain growth (Rivas et al., 2005; Stadt et al., 2007; Tomé and Burkhart, 1989). However, the two explanations are functionally equivalent and suggest that to adequately predict growth responses of Scots pine, the structure and functioning of the surrounding stand must be estimated in more detail than using simple indices (see also Olano et al. 2009). Stand models that account for species identity and the detailed structure of individual trees could be a potential tool for increasing structural precision and thus in estimating factors that are difficult to characterize with simple measurements (Cournede et al., 2008; Sievänen et al., 2008).

In Scots pine, the neighboring silver birch trees accelerated Scots pine height growth, compared with conspecific neighbors, while diameter growth was not affected. Valkonen and Ruuska (2003) reported that height growth was not affected, while diameter growth decreased in young stands as the proportion of silver birch within the stand increased. Mielikäinen (1980), in turn, found that the volume growth of pine was poorer in mixed stands than in pure pine stands when the proportion of silver birch exceeded 20\%; at lower birch density a slight positive effect was suggested. Lappi-Seppälä (1930) reported that pine grew faster in silver birch mixtures, but the results were criticized by Mielikäinen (1980) for not controlling potential differences in site fertility. Our results suggest that the growth increase observed by Lappi-Seppälä 
(1930) may have been a true increase, although at our stands it may have been partially related to the relatively low density of trees.

The annual Scots pine shoots from the last $2 \mathrm{y}$ were shortest with silver birch as neighbors and longest with Siberian larch, which suggests a potential for flexible adjustment of growth allocation within the crown, depending on the neighboring species. Similarly, branch number per crown length was highest with Siberian larch and lowest with silver birch as neighbors. Potential differences in light interception between birch and larch as neighbors could explain the flexible adjustment of shoot length, because pine shoots respond positively to irradiance levels, especially at fertile sites (Niinemets and Lukjanova, 2003).

A single competition index, $\mathrm{CI}_{4}$, had a consistently negative effect on all variables that were modified by neighbor identity in Scots pine, i.e. on whorl distance, individual shoot length, and branch number per crown length. This confirms that competition was strong enough to influence tree traits, despite the low overall stand density. However, it does not necessarily indicate superior performance of $\mathrm{CI}_{4}$ compared with other indices, because the differences in explanatory power between different indices were often negligible.

Taken together, the fact that the CIs explained both the current tree traits and past growth lends support to the assumption that it was plausible to use the current values of the indices to estimate past competition. If the growth rate of the subject tree in relation to its neighbors remains sufficiently steady throughout the study period, then the current value of the CI based on $d_{j}, L_{i j}$, and $h_{j}$ will show a strong positive correlation with its past value, and there will be no interactive effect of the CI by neighboring species on the variables that constitute the CI. On the other hand, dissimilarity of past growth rate in relation to different neighboring species will increase the probability of a significant CI by neighboring species interaction, since the value of past CIs must have been dependent on neighbor identity. In such cases, e.g. height increment in silver birch and diameter growth in Siberian larch, it is not possible to separate the effect of neighbor identity from the level of competition. Lintunen and Kaitaniemi (2010), however, demonstrate that in silver birch many branch-level structural variables are affected by the interactive effects of neighbor identity and competition, which suggests that the result we obtained here may also have been a true interaction.

Overall, the tests with silver birch indicated that the effect of competition alone was more prominent than the effect of neighbor identity. Diameter growth and individual shoot length were directly reduced by the level of competition, whereas height growth was accelerated by competition in the presence of Siberian larch or Scots pine. Both Lappi-Seppälä (1930) and Mielikäinen (1980) also reported that silver birch grew faster in mixtures with Scots pine. In Siberian larch, the average height increment was reduced by competition alone and diameter growth was reduced by competition, especially with silver birch.

Due to the limited density range of neighboring species, our results do not allow safe prediction of stand-level responses, but support previous suggestions that the growth of both sil- ver birch and Scots pine may benefit from mixed stands. A simple extrapolation of the growth observed in height and diameter suggests that both pine and birch would grow faster in mixed than in pure stands. Siberian larch, in turn, showed negative responses to interspecific neighbors, but this reduction in growth appeared to be counterbalanced by an increase in pine or birch growth. Thus, the use of Siberian larch in mixtures also shows potential for maintaining favorable standlevel yields, although the outcome may be dependent on the exact proportions of different species.

Acknowledgements: We thank Sauli Valkonen for making possible the use of four experimental stands of the Finnish Forest Research Institute (Metla) in the study. We also thank Niina Miettinen, Reijo Pankka, Laura Rantala, Suvi Ruuskanen, and Tiina Sauvula for field and laboratory assistance. We also thank anonymous referees for their thoughtful suggestions. The study was financed by the Academy of Finland.

\section{REFERENCES}

Akaike H., 1973. Information theory and extension of the maximum likelihood principle. In: 2nd International Symposium in Information Theory, Budapest, Hungary, Akademiai Kiado, pp. 267-281.

Anonymous, 2001. Hyvän metsänhoidon suositukset. Publications of Forestry Development Centre Tapio, Libris Oy, Helsinki, Finland (in Finnish).

Canham C.D., LePage P.T., and Coates K.D., 2004. A neighborhood analysis of canopy tree competition: effects of shading versus crowding. Can. J. For. Res. 34: 778-787.

Casper B.B. and Jackson R.B., 1997. Plant competition underground. Annu. Rev. Ecol. Syst. 28: 545-570.

Cournède P.H., Mathieu A., Houllier F., Barthélémy D., and de Reffye P., 2008. Computing competition for light in the GREENLAB model of plant growth: a contribution to the study of the effects of density on resource acquisition and architectural development. Ann. Bot. 101: $1207-1219$.

De Luis M., Raventós J., Cortina J., Moro M.J., and Bellot J., 1998. Assessing components of a competition index to predict growth in an even-aged Pinus nigra stand. New For. 15: 223-242.

Frivold L.H. and Frank J., 2002. Growth of mixed birch-coniferous stands in relation to pure coniferous stands at similar sites in south-eastern Norway. Scand. J. For. Res. 17: 139-149.

Goldberg D.E. and Barton A.M., 1992. Patterns and consequences of interspecific competition in natural communities - a review of field experiments with plants. Am. Nat. 139: 771-801.

Kalliokoski T., Pennanen T., Nygren P., Sievänen R., and Helmisaari H.-S., 2010. Belowground interspecific competition in mixed boreal forests: fine root and ectomycorrhiza characteristics along stand developmental stage and soil fertility gradients. Plant Soil, 330: 73-89.

Kellomäki S., Ikonen V.P., Peltola H., and Kolström T., 1999. Modelling the structural growth of Scots pine with implications for wood quality. Ecol. Model. 122: 117-134.

Kelty M.J., 2006. The role of species mixtures in plantation forestry. For. Ecol. Manage. 233: 195-204.

Knoke T., Ammer C., Stimm B., and Mosandl R., 2008. Admixing broadleaved to coniferous tree species: a review on yield, ecological stability and economics. Eur. J. For. Res. 127: 89-101.

Lappi-Seppälä M., 1930. Untersuchungen über die Entwicklung gleichaltriger Mischbestände aus Kiefer und Birke, basiert auf Material der Südhälfte von Suomi (Finland). Commun. Inst. For. Fenn. 15: 1-243. 
Lintunen A. and Kaitaniemi P., 2010. Responses of crown architecture in Betula pendula to competition are dependent on the species of neighbouring trees. Trees 24: 411-424.

Littell R.C., Milliken G.A., Stroup W.W., and Wolfinger R.D., 1996. SAS system for mixed models. SAS Institute Cary, NC.

Meng S.X., Rudnicki M., Lieffers V.J., Reid D.E.B., and Silins U., 2006. Preventing crown collisions increases the crown cover and leaf area of maturing lodgepole pine. J. Ecol. 94: 681-686.

Mielikäinen K., 1980. Structure and development of mixed pine and birch stands. Commun. Inst. For. Fenn. 99: 1-82.

Nichols J.D., Bristow M., and Vanclay J.K., 2006. Mixed-species plantations: prospects and challenges. For. Ecol. Manage. 233: 383-390.

Niinemets U. and Lukjanova A., 2003. Needle longevity, shoot growth and branching frequency in relation to site fertility and within-canopy light conditions in Pinus sylvestris. Ann. For. Sci. 60: 195-208.

Olano J.M., Laskurain N.A., Escudero A., and De La Cruz M., 2009. Why and where do adult trees die in a young secondary temperate forest? The role of neighbourhood. Ann. For. Sci. 66: 105.

Quail P.H., 2002. Photosensory perception and signalling in plant cells: new paradigms? Curr. Opin. Cell Biol. 14: 180-188.

Rivas J.J.C., González J.G.Á., Aguirre O., and Hernández F.J., 2005. The effect of competition on individual tree basal area growth in mature stands of Pinus cooperi Blanco in Durango (Mexico). Eur. J. For. Res. 124: 133-142.

Rouvinen S. and Kuuluvainen T., 1997. Structure and asymmetry of tree crowns in relation to local competition in a natural mature Scots pine forest. Can. J. For. Res. 27: 890-902.

Shorohova E., Kuuluvainen T., Kangur A., and Jõgiste K., 2009. Natural stand structures, disturbance regimes and successional dynamics in the Eurasian boreal forests: a review with special reference to Russian studies. Ann. For. Sci. 66: 201.
Sievänen R., Perttunen J., Nikinmaa E., and Kaitaniemi P., 2008. Toward extension of a single tree functional-structural model of Scots pine to stand level - effect of the canopy of randomly distributed, identical trees on development of tree structure. Funct. Plant Biol. 35: 964975 .

Singer J.D., 1998. Using SAS PROC MIXED to fit multilevel models, hierarchical models, and individual growth models. J. Educ. Behav. Stat. 23: 323-356.

Sinoquet H. and Rivet P., 1997. Measurement and visualization of the architecture of an adult tree based on a three-dimensional digitising device. Trees 11: 265-270.

Spilke J., Piepho H.P., and Hu X., 2005. Analysis of unbalanced data by mixed linear models using the MIXED procedure of the SAS system. J. Agron. Crop. Sci. 191: 47-54.

Stadt K.J., Huston C., Coates K.D., Feng Z.L., Dale M.R.T., and Lieffers V.J., 2007. Evaluation of competition and light estimation indices for predicting diameter growth in mature boreal mixed forests. Ann. For. Sci. 64: 477-490.

Strand M., Lofvenius M.O., Bergsten U., Lundmark T., and Rosvall O., 2006. Height growth of planted conifer seedlings in relation to solar radiation and position in Scots pine shelterwood. For. Ecol. Manage. 224: $258-265$.

Tchebakova N.M., Rehfeldt G.E., and Parfenova E.I., 2003. Redistribution of vegetation zones and populations of Larix sibirica Ledeb. and Pinus sylvestris L. in Central Siberia in a warming climate. Siberian Ecol. J. 10: 677-686.

Tomé M. and Burkhart B.E., 1989. Distance-dependent competition measures for predicting growth of individual trees. For. Sci. 35: 816-831.

Valkonen S. and Ruuska J., 2003. Effect of Betula pendula admixture on tree growth and branch diameter in young Pinus sylvestris stands in southern Finland. Scand. J. For. Res. 18: 416-426. 